\title{
Development of Infrared Radial Radiation Dryer for Paddy
}

\author{
Nuttaphon Saelim, Krawee Treeamnuk, Tawarat Treeamnuk
}

\begin{abstract}
An infrared radial radiation heating system was developed for drying paddy. A cylindrical drying chamber was installed 1,200 W of infrared heater at center for radial radiation heating. Paddy drying behavior and performance of the paddy dryer in terms of drying rate (DR), specific energy consumption (SEC) and quality of paddy i.e. head rice yield (HRY) and whiteness index (WI) were evaluated by drying 15 kg of paddy with initial moisture content of $23-26 \%$ (w.b.) by using the drying conditions of $80^{\circ} \mathrm{C}$ of drying temperature, $334.2 \mathrm{~m}^{3} / \mathrm{min}$ of air flow rate and $0.837,1.228$ and $1.875 \mathrm{~kg} / \mathrm{min}$ of thin layer paddy flow rate. The results indicated that the drying rate and head rice yield were increased when increase the flow rate of thin layer paddy but in contrast of SEC and whiteness index.
\end{abstract}

Keywords—paddy dryer, infrared, radial radiation

\section{Introduction}

Rice is one of the major food crops in the world and global paddy production in year 2016 is 751.9 million tons [1]. Normally, fresh paddy harvested at moisture content 24$35 \%$ dry basis higher than safety storage moisture content, so, drying is the important post-harvest process.

The drying paddy process can be done in several techniques. For the example, dehumidification by solar energy has the advantage is easy to operation and low energy costs but the disadvantage is cannot control the heat source. Dehumidification by dryer has the advantage is can be operating in every climate and can control moisture content level, but the disadvantage is high operating cost. In present, infrared (IR) drying has been gaining traction in agro-industry because of its high thermal efficiency [2]. The IR radiation is band of electromagnetic spectrum cover wavelengths in the range of $0.75-1000 \mu \mathrm{m}$. Several investigations have been performed on the IR heating of foodstuffs for different purposes such as drying, cooking, baking, roasting, and blanching [3]. For drying, IR radiation can penetrate into the material result in the inside material is high temperature than the surface material. As a result, the outer surface of material does not wrinkle and properties of the product are similar to the material before drying.

\section{Nuttaphon Sealim}

School of Mechanical Engineering, Suranaree University of Technology Thailand

Krawee Treeamnuk

School of Mechanical Engineering, Suranaree University of Technology Thailand

Tawarat Treeamnuk

School of Agricultural Engineering, Suranaree University of Technology Thailand
IR drying has been the subject of investigations by several recent researchers for several agricultural materials i.e. Sharma et al. [4] were drying onion slice with IR. The thin layer drying of onion slices was carried out at of 300 , 400 and 500W of IR power levels, air temperatures of 35, 40 and $45^{\circ} \mathrm{C}$ and air velocities of $1.0,1.25$ and $1.5 \mathrm{~m} / \mathrm{s}$. The drying occurred in the falling rate period. Drying rate increased with increase in IR power at a given air temperature and velocity and thus reduced the drying time. The drying time increased with increase in air velocity at a given IR power and air temperature because of the increased cooling effect at the surface of the product. A. Ruiz Celma et al. [5] were studied thin-layer IR drying behavior of industrial grape by-products in the temperature range from 100 to $160^{\circ} \mathrm{C}$. They found that, the drying rate was increase with temperature, thus reducing the total drying time. In particular, as drying temperature was raised from $100^{\circ} \mathrm{C}$ up to $160^{\circ} \mathrm{C}$, the time period needed to reduce the moisture content of the sample from $204.32 \%$ down to $38.89 \%$ by weight (dry basis) decreased from 60.5 to 21 minutes. $\mathrm{H}$. Umesh Hebbar et al. [6] were developed a combined IR and hot air dryer for vegetables. The performance evaluation studies indicated that combination drying of carrot and potato at $80^{\circ} \mathrm{C}$ with air at a velocity of $1 \mathrm{~m} / \mathrm{s}$ and temperature of $40^{\circ} \mathrm{C}$ reduced the drying time by $48 \%$, besides consuming less energy $(63 \%)$ compared to hot air heating. Combination drying also gave better results over infrared heating alone. The energy utilization efficiency of the dryer was estimated to be $38 \%$ for both carrot and potato drying.

For paddy drying by IR, Juckamas Laohvanich and Seree Wongpichet [7] were study behavior of paddy drying process by GAS-FIRED INFRARED (GIR). In the experiment, the tray was vibrated with frequency at 450 cycles/min and the amplitude of vibration was approximately $0.01 \mathrm{~m}$ in the vertical direction, conducted using $0.5 \mathrm{~kg}$ of wet paddy samples with three replications at four initial moisture contents $\left(\mathrm{M}_{0}\right)$ of $0.22,0.27,0.32$ and 0.37 decimal (d.b.). Three IR radiations were applied at specific emitted maximum wavelengths ( $\operatorname{lmax}$ ), which were close to the absorption peak of moist materials in the infrared ray (IR) range of $2.70,2.58$ and $2.47 \mathrm{~mm}$. The drying experiment found that the drying time was significantly reduced with the increase of intensity level (decreased IR peak wavelength value, lmax), as higher energy was absorbed by the paddy. The effect of the drying process on wet paddy at different initial moisture content levels was observed to be that GIR drying time was influential in causing an increase in head rice yield. In addition, both GIR drying and tempering time directly affected a decrease in the whiteness index. Ipsita Das et al. [8] were study behavior of paddy drying process by IR. In the experiment, the soaked paddy was placed on the drying tray to the desired depth and subjected to vibration in IR field. The frequency and amplitude of the vibration was held at the optimum level of $21-22 \mathrm{~Hz}$ and $8-9 \mathrm{~mm}$. The drying experiments were conducted at five radiation intensities 
Proc. of the Eighth International Conference On Advances in Mechanical, Aeronautical and Production Techniques - MAPT 2018 Copyright (C) Institute of Research Engineers and Doctors. All rights reserved. ISBN: 978-1-63248-147-4 doi: 10.15224/ 978-1-63248-147-4-24

$\left(1509,2520,3510,4520\right.$ and $\left.5514 \mathrm{~W} / \mathrm{m}^{2}\right)$ for four different grain bed depths (single kernel thickness of 3, 6, 12 and 25 $\mathrm{mm})$. The drying experiment found that the drying rate increase with increase in radiation intensity, while decrease with the increase in bed depth. Mojtaba Tohidi et al. [9] were study energy and quality attributes for fix deep bed drying of paddy. The drying experiment using centrifugal fan blew air into a heater containing $7 \mathrm{~kW}$ electrical heating coils and then passed the heated air into drying chamber. In experiments were conducted freshly harvested paddy at different levels of drying air parameters including temperature $\left(\mathrm{T}=40,50,60,70\right.$ and $\left.80^{\circ} \mathrm{C}\right)$, velocity $(\mathrm{V}=0.5$, 0.8 and $1.1 \mathrm{~m} / \mathrm{s})$ and relative humidity $(\mathrm{RH}=40 \%, 50 \%, 60 \%$ and $70 \%$ ). The results of energy analysis showed that the energy efficiency was improved at higher temperatures, and lower levels of velocity and relative humidity for drying air. Furthermore, it was found that the number of fissured kernels was directly related to drying rate where damaged kernels increased with increasing drying rate.

Although several reports are available on the IR or IR combination with hot air for paddy drying, no reports on IR radial radiation dryer. The objective of this research was to develop a continuous flow paddy dryer with IR radial radiation and evaluate performance of the paddy drying.

\section{Materials and methods}

\section{A. Paddy sample in experiment}

Samples of fresh long-grain paddy of Khao Dawk Mali 105 variety with initial moisture contents about 23-26\% (w.b.) were used for all tests. The samples were harvested in Nakhon Ratchasima (Thailand's northeast region) in November 2017.

\section{B. Development of dryer}

A continuous flow with IR radial radiation dryer was developed for drying of paddy. The schematic picture of the dryer is given in Fig. 1. The dryer consists of two concentric circular cylinders, which the paddy drying chamber is height of $1 \mathrm{~m}$. The inner cylinder has diameter of $26.5 \mathrm{~cm}$ made from glass pieces which welding gap of $1 \mathrm{~mm}$ consistently and the outer cylinder has diameter of $29.5 \mathrm{~cm}$ made from perforated $(1.75 \mathrm{~mm})$ steel sheet cause to the $3 \mathrm{~mm}$ of paddy drying layer. The hopper on top of the chamber use to feed paddy grain into the annular space drying chamber. An infrared heater (tube type) of $1200 \mathrm{~W}$ having diameter of 17 $\mathrm{mm}$ and heating length of $1000 \mathrm{~mm}$ was fitted at center of cylinder along surface of the drying chamber. A $24 \mathrm{~V} \mathrm{DC}$ blower blows the surround air into the drying chamber passes through grain moving downward and pick up moisture from paddy and then comes out of the outer perforated cylinder. Thin layer paddy flow rate controller made from superlene, it has diameter $10 \mathrm{~cm}$, length $10 \mathrm{~cm}, 4$ boring groove which dimension of $2 \times 2 \times 10 \mathrm{~cm}$, driven with $12 \mathrm{~V}$ DC. The temperature of paddy while drying was measure by 4 Thermocouples Type $\mathrm{K}$. The whole dryer is supported by the structure fame. The Fig. 2 showed paddy dryer in experiment.

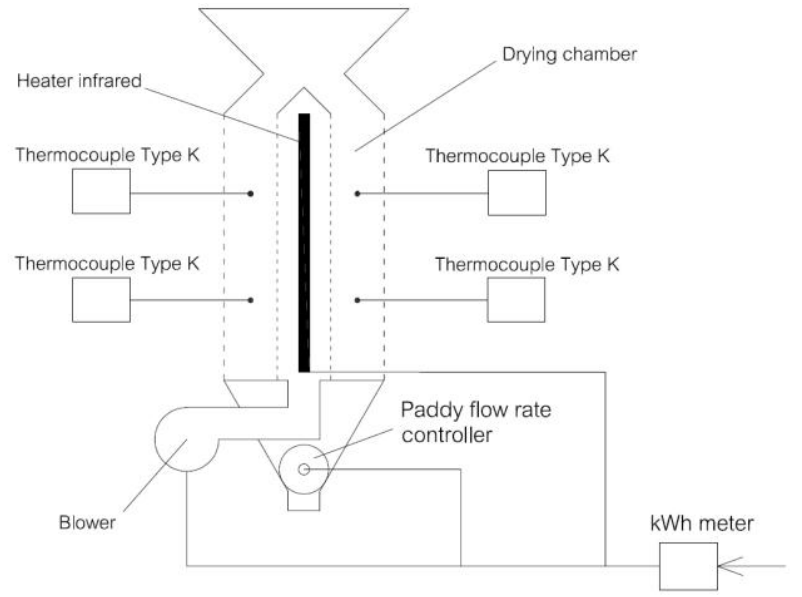

Figure 1. Schematic picture of the IR paddy dryer.

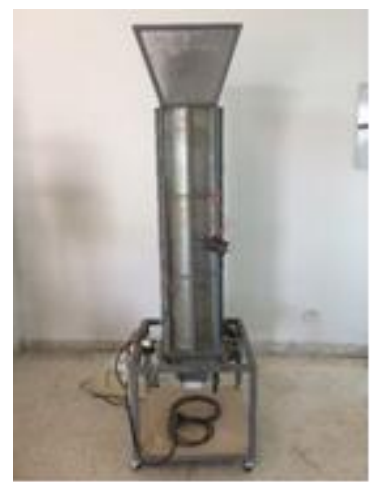

Figure 2. The IR paddy dryer in experiment.

\section{Experiment of paddy drying}

The drying experiments were used to evaluate the performance of the dryer. The effect of thin layer flow rate on the performance of paddy drying in terms of drying rate, SEC, HRY and WI. The heating time by infrared radiation of paddy depend on thin layer paddy flow rate, it affect to moisture content level of paddy and energy of drying process. In the experiment, running system 30 minutes before paddy drying for temperature of system steady, set the flow rate of thin layer paddy of $0.837,1.228$ and 1.875 $\mathrm{kg} / \mathrm{min}$, and air flow rate was fix at $334.2 \mathrm{~m}^{3} / \mathrm{min}$ (measure by anemometer), contain $15 \mathrm{~kg}$ of paddy in chamber and then moisture content of samples were measured every 18 , 13 and $8 \mathrm{~min}$ (vary from thin layer paddy flow rate) by moisture tester meter (model SB900, The Steinlite Corporation, Atchison, Kansas USA). Paddy samples were circulated drying until final moisture content is about $14 \%$ (w.b.). During the experiments, the total electrical energy (include blower, thin layer paddy flow rate controller and infrared heater) of drying process were measured by kWhmeter. All drying conditions were test in 3 replicates.

\section{Drying behavior and performance of dryer}

In this studied, paddy drying behavior and the performance of the IR dryer that influenced from thin layer paddy flow rate in terms of DR, SEC, HRY and WI were investigated. 
Proc. of the Eighth International Conference On Advances in Mechanical, Aeronautical and Production Techniques - MAPT 2018 Copyright (C) Institute of Research Engineers and Doctors. All rights reserved.

ISBN: 978-1-63248-147-4 doi: 10.15224/ 978-1-63248-147-4-24

- Paddy drying behaviors

Paddy drying behaviors in each conditions of thin layer paddy flow rate are shown in drying curve. The moisture content values from experiments were converted into the moisture ratio (MR). The dimensionless moisture ratio can be calculated as in (1). However, the moisture ratio was simplified to $M_{t} / M_{i}$, where $M_{t}$ and $M_{i}$ are the moisture content at any given time and the initial moisture content, respectively, since in IR drying, samples may be dried as much as dry matter content (equilibrium moisture equal to zero) [10].

$$
\mathrm{MR}=\frac{\mathrm{M}_{\mathrm{t}}}{\mathrm{M}_{\mathrm{i}}}
$$

- Drying rate (DR)

The DR determined from water removal from paddy per drying time. It can be calculated as in (2), where $\mathrm{W}_{\mathrm{i}}, \mathrm{W}_{\mathrm{f}}$ and $\mathrm{t}$ are the initial weight of paddy, final weight of paddy and drying time, respectively.

$$
\mathrm{DR}=\frac{\mathrm{W}_{\mathrm{i}}-\mathrm{W}_{\mathrm{f}}}{\mathrm{t}}
$$

- $\quad$ Specific energy consumption (SEC)

The SEC determined from total energy of drying process (MJ) per kilograms of water removal from paddy. It can be calculated as in (3), where $\mathrm{E}$ is the total energy of drying process (measured by kWh-meter).

$$
\mathrm{SEC}=\frac{3.6 \mathrm{E}}{\mathrm{W}_{\mathrm{i}}-\mathrm{W}_{\mathrm{f}}}
$$

- $\quad$ Head rice yield (HRY)

Taking $125 \mathrm{~g}$ of paddy samples after drying with the IR dryer and paddy sample from solar drying (control) at moisture content about 14\% (w.b.). The both paddy samples were milled by laboratory rubber roll huller (model NW-150) and then brown rice was whitened by an abrasive roller polisher. Separate head rice and broken rice from rice samples by screening machine, weigh the head rice and record data. HRY can be calculated as in (4).

$$
\text { HRY }=\frac{\text { weight of head rice }}{\text { weight of paddy }} \times 100 \%
$$

- Whiteness index (WI)

From the rice sample, the rice whiteness of milled rice was measured using a digital whiteness tester (Kett C-300, Kett Electronic Laboratory Corporation, Tokyo, Japan).

\section{RESULTS AND DISCUSSION}

\section{A. Drying curve}

Paddy drying behavior at difference level of thin layer paddy flow rate shown in Fig. 3 and Fig. 4. The experiments results shown that most of behavior drying process occur in the falling rate period. In the initial period, moisture content reduce rapidly and after that moisture content reduce slowly because water evaporation process took place initially at the surface of the paddy samples, but it begins to be less important as the drying time was added. Considering influenced of thin layer paddy flow rate found that the thin layer paddy flow rate increase affect to mass transfer increase because the paddy can be more moving contact with fresh air than the lower flow rate level.

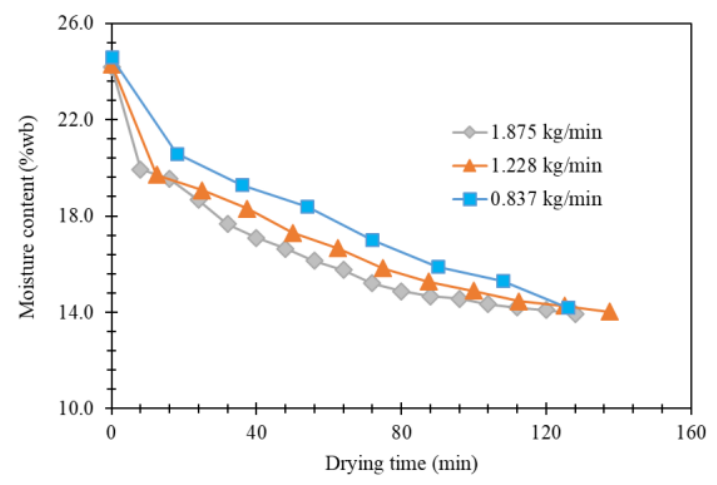

Figure 3. Variation in the paddy moisture content for different levels of thin layer paddy flow rate.

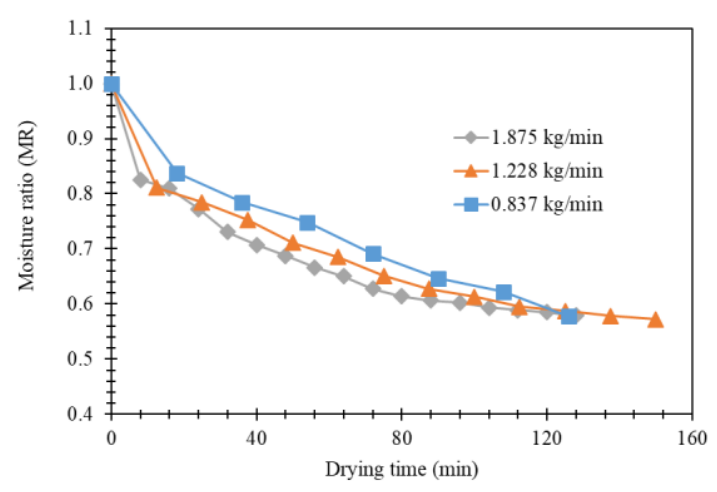

Figure 4. Variation in the paddy moisture ratio for different levels of thin layer paddy flow rate.

\section{B. Drying rate (DR)}

DR of paddy drying is the rate of water removal from paddy kernel. Considering influenced of thin layer paddy flow rate found that the thin layer paddy flow rate increase affect to DR increase because thin layer paddy flow rate increase affect to the paddy can be transfer more moisture to air than lower flow rate levels (Fig.5).

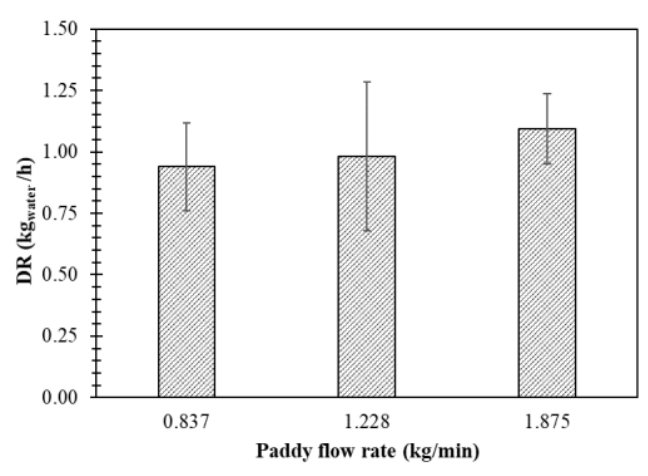

Figure 5. Drying rate of paddy dryer. 
Proc. of the Eighth International Conference On Advances in Mechanical, Aeronautical and Production Techniques - MAPT 2018 Copyright (C) Institute of Research Engineers and Doctors. All rights reserved. ISBN: 978-1-63248-147-4 doi: 10.15224/ 978-1-63248-147-4-24

\section{Specific energy consumption}

SEC is the total energy use for removal water from paddy kernel. Considering influenced of thin layer paddy flow rate found that the thin layer paddy flow rate increase affects to decrease SEC because thin layer paddy flow rate increase affect to the paddy can be transfer more moisture to air than lower flow rate level (Fig.6). Therefore, the drying process for evaporate moisture to desired moisture content use less time.

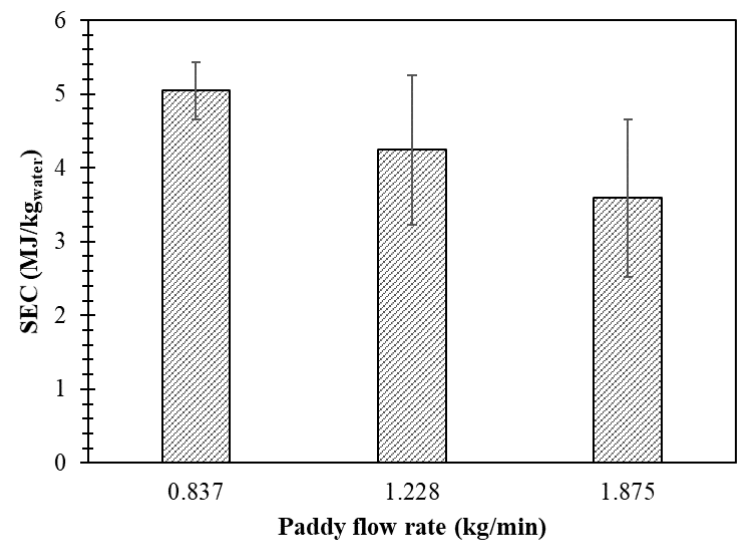

Figure 6. Specific energy consumption of paddy dryer.

\section{Effect of thin layer paddy flow rate with quality of paddy after drying process}

- Head rice yield (HRY)

Considering influenced of thin layer paddy flow rate found that the thin layer paddy flow rate increase affects to increase HRY (Fig. 7) because the higher thin layer paddy flow rate takes the paddy kernel stay in chamber less time than the lower flow rate, so, paddy kernel at lower thin layer paddy flow rate receive heat from infrared radiation for a long time cause the damage of paddy increased when decreasing thin layer paddy flow rate. When compare HRY from IR drying with control (sun drying) found that all condition of IR drying have lower HRY than control.

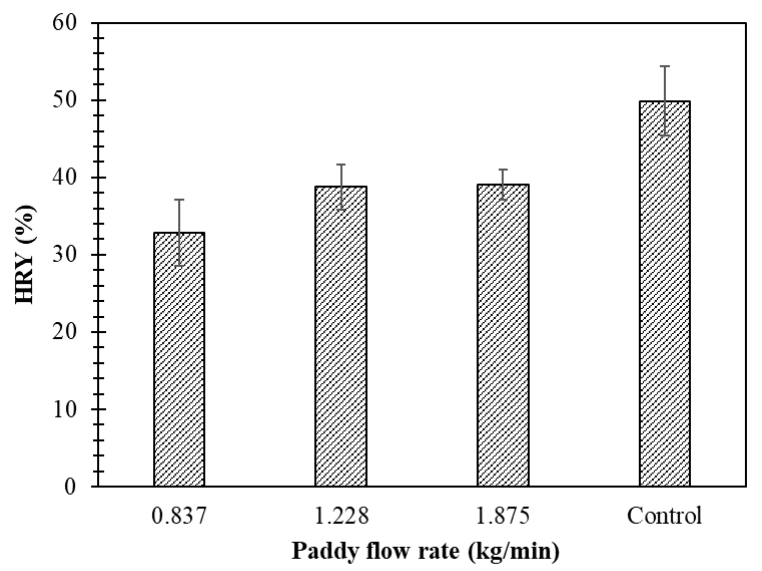

Figure 7. Head rice yield of paddy.

\section{- Whiteness index (WI)}

Consideration WI value of control sample and samples of paddy after IR drying found that the samples of paddy after IR drying have WI close to control sample. Consider effect of thin layer paddy flow rate affect to WI found that WI of each thin layer paddy flow rate are tend to decrease when thin layer paddy flow rate increase.

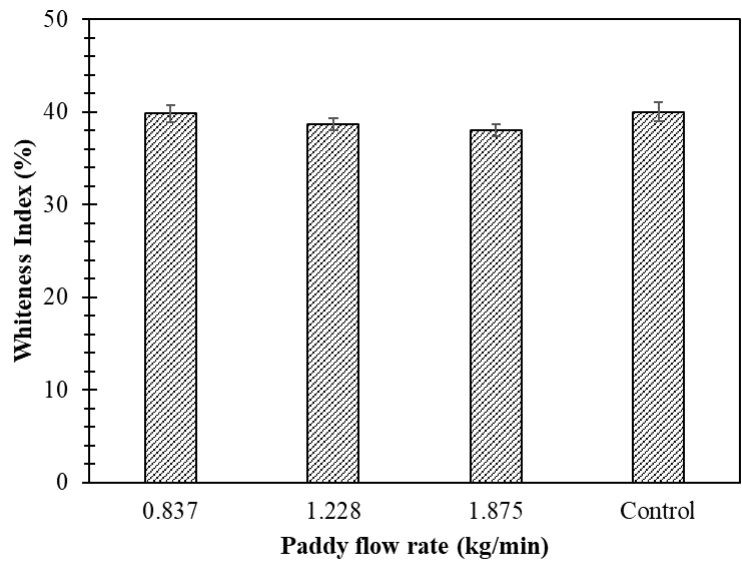

Figure 8. Whiteness index of rice.

\section{Conclusion}

From experiment of the paddy drying by IR drying with different thin layer paddy flow rate found that the flow rate of thin layer paddy was increased affect to DR and HRY were increase but SEC and WI were decrease. The thin layer paddy flow rate of $1.875 \mathrm{~kg} / \mathrm{min}$ is suitable for paddy drying because this condition gave the highest DR and HRY and lowest in SEC with WI close to control.

\section{Acknowledgment}

The author would like to thank the Biosystem Engineering and Technology Research Laboratory and Suranaree University of Technology for support this research.

\section{References}

[1] Food and Agriculture Organization of the United Nation, "Rice Market Monitor," vol. XX, No. 1, Apr. 2017.

[2] Juckamas Laohavanich, and Seree Wongpichet, "Thin layer drying model for gas-fired infrared drying of paddy," Songklanakarin J. Sci. Technol, vol.30 (3), pp. 343-348, May-Jun 2008.

[3] Dariush Zare, Hossein Naderi, and Mohsen Ranjbaran, "Energy and quality attributes of combined hot-air/infrared drying of paddy," Drying Technology, vol. 33, pp 570-582, Febury 2015.

[4] G.P. Sharma, R.C. Verma, and Pankaj Pathare, "Mathematical modeling of infrared radiation thin layer drying of onion slices," Journal of Food Engineering, vol. 71(3), pp. 282-286, December 2005.

[5] A. Ruiz Celma, F.López-Rodríguez, and F.Cuadros, "Experimental modelling of infrared drying of industrial grape by-products," Food and Bioproducts Processing, vol. 87(4), pp. 247-253, December 2009.

[6] H. Umesh Hebbar, K.H. Vishwanathan, and M.N. Ramesh, "Development of combined infrared and hot air dryer for vegetables," Journal of Food Engineering, vol. 65(4), pp.557.563, December 2004.

[7] Juckamas Laohavanich, and Seree Wongpichet, "Drying characteristrics and milling quality aspects of paddy dried gas-fired 
Proc. of the Eighth International Conference On Advances in Mechanical, Aeronautical and Production Techniques - MAPT 2018

Copyright (C) Institute of Research Engineers and Doctors. All rights reserved.

ISBN: 978-1-63248-147-4 doi: 10.15224/ 978-1-63248-147-4-24

infrared," Journal of Food Process Engineering, vol. 32(3), pp. 442461, June 2009.

[8] Ipsita Das, S.K. Das, and Satish Bal, "Drying kinetics of high moisture paddy undergoing vibration-assisted infrared (IR) drying," Journal of Food Engineering, vol.95(1), pp. 166-171, November 2009.

[9] Mojtaba Tohidi, Morteza Sadeghi, and Mehdi Torki-Harchegani, "Energy and quality aspects for fixed deep bed drying of paddy," Renewable and Sustainable Energy Reviews, vol.70, pp. 519-528, April 2017.

[10] A. Ruiz Celma, F.Cuadros, and F.López-Rodríguez, "Characterisation of industrial tomato by-products from infrared drying process," Food and Bioproducts Processing, vol. 87 (4), pp. 282-291, December 2009.

\section{About Authors:}

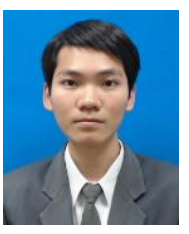

Nuttaphon Saelim was born in Nakhon Ratchasima province, Thailand on April 7, 1994. He received his $1^{\text {st }}$ class honors B.Eng.(Mechanical Engineering) from Suranaree University of Technology, Thailand. Currently, he is a master degree student in Mechanical Engineering Program, Suranaree University of Technology.

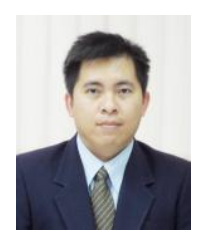

Krawee Treeamnuk, D. Eng. $\mathrm{He}$ is currently an Assistant Professor at School of Mechanical Engineering, Institute of Engineering, Suranaree University of Technology (Thailand). His research interest is mainly in the area of postharvest machines and process, nondestructive technique, thermal process in agricultural system.

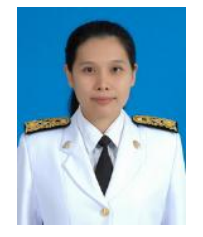

Tawarat Treeamnuk, D. Eng. She is currently an Assistant Professor at School of Agricultural engineering, Institute of Engineering, Suranaree University of Technology (Thailand). Her areas of research interests are food processing, post-harvest technology, drying. 